\title{
Quantitative assessment of evacuation measures in flood-prone areas
}

\author{
Bas Kolen ${ }^{1,2}$, Paul Dannenberg2 and Pieter van Gelder ${ }^{2}$ \\ ${ }^{1}$ HKV Consultants, Botter 11-29, 8232 JN Lelystad, The Netherlands \\ ${ }^{2}$ Delft University of Technology, PO Box 5, 2600 AA Delft, Netherlands
}

\begin{abstract}
Evacuation is a tool to minimize the loss of life and economic damages in flood (threat) scenarios. The Dutch programs 'Water and Evacuation' and 'Wave2020' focused on the improvement of emergency preparation. Effort has been placed to improve information management, evacuation preparation, decision making and to increase risk awareness among professionals and citizens. The question is however how to incorporate these measures into account in a quantitative risk assessment. In this paper we focus on the improvements of the departure curve by emergency planning. This research method builds on the warning guidebook and a questionnaire developed by the USACE (Mileti and Sorensen 2015) and how evacuation is taken into account in the Dutch flood risk approach (ENW 2017). In a case study the PBL method (Pleijter and Kolen 2016), a macro model to determine evacuation and loss of life is compared to LifeSim, an agent-based models. In this research we concluded that improvements in the departure curve do not result in a significant increase of effectiveness of preventive evacuation in the Netherlands because the (national) road network is already overcrowded. Only when the traffic network has free capacity left an improvement of the departure curve will increase effectiveness of evacuation.
\end{abstract}

\section{Introduction}

In 2017 the Netherlands adopted a new flood risk management approach. The approach is based on the concept of Multiple Layered Safety which is based on three layers: layer 1 prevention, layer 2 land use planning and layer 3 emergency management (ENW 2017). In the quantitative risk-assessment the estimation of loss of life is considered, as well as the effectiveness of evacuation. Evacuation is a tool to minimise the loss of life and economic damage in (potential) dangerous events (Maaskant et al 2009a, Kolen et al 2013). Events prior to the expected onset of a flood can be classified in time periods that are displayed in Table 1 (Mileti and Sorensen 2017). These time periods are:

- Warning issuance delay time: The time it takes for authorities to reach a decision to issue a warning once they have detected the hazard or have been notified of the hazard.

- Warning diffusion: The process of how efficiently information spreads through the population at risk. It is the period after the first warning is issued and the time people receive this warning.

- Mobilisation or protective action initiation: The time between when an alert or warning is received by a person at risk and the initiation of a recommended protective action by that person (such as getting in their car).
- Net available time for evacuation: The net available time for evacuation is the period between the beginning of the evacuation and the onset of the disaster. This is the time left for people to reach a shelter or leave the threatened area.

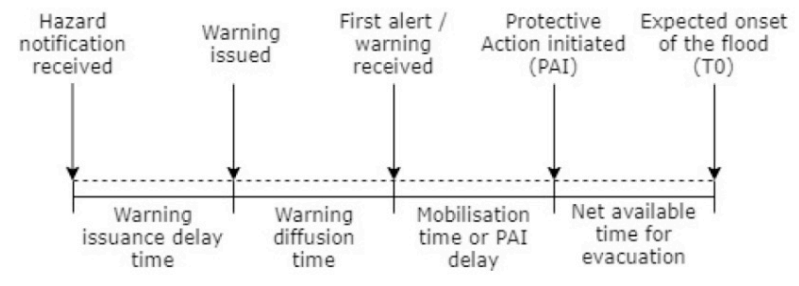

Table 1: Evacuation time line

The effectiveness of an evacuation is determined by the expected ratio of inhabitants of an area that can evacuate out of an area prior to a flood. The effectiveness of evacuation depends on the available time and the required time for evacuation. Loss of life is based on the number of inhabitants who have not been evacuated preventively, which is determined by the total number of inhabitants multiplied by 1 minus the evacuation fraction. Mortality functions, which are used to calculate loss of life, are a function of water depths (Jonkman 2007, Maaskant et al. 2009b), velocities and rise rates. Recent research shows that also the location and circumstances

\footnotetext{
a Corresponding author: b.kolen@hkv.nl

DOI 10.3311/FLOODRisk2020.19.6
} 
where people are exposed (in a house, a shelter, on the road) influence loss of life (Kolen et al 2013).

The Dutch programs 'Water and Evacuation' and 'Wave2020' focused on the improvement of emergency preparation. Effort has been placed to improve information management, evacuation preparation, decision making and to increase risk awareness among professionals and citizens. The question is however how to incorporate these measures into account in a quantitative risk assessment. The City of Dordrecht has described their strategy in their water safety plan. The water safety plan also includes an investment agenda in the field of crisis communication that should increase the evacuation effectiveness in time. Dordrecht uses the PBL evacuation and loss of life model to determine what results can be expected by adopting a certain evacuation strategy. The PBL model (Pleijter and Kolen 2016) is a macro model which means the population is considered as a whole instead of modelling each person separately. In the PBL model the warning diffusion curve and personal action initiation curve are combined into a single departure curve.

The United States Army Corps of Engineers (USACE) collected data from numerous evacuations and defined important factors that influence the warning issuance delay time, warning diffusion time and personal action initiation time. From these studies they developed an assessment method which includes a questionnaire that can estimate the expected warning issuance delay time, warning diffusion time and personal action initiation time for an area.

\section{Research question}

The effectiveness of an evacuation is determined by the expected ratio of inhabitants of an area that can evacuate out of an area prior to a flood. The effectiveness of evacuation depends on the available time and the required time for evacuation. Loss of life is based on the number of inhabitants who have not been evacuated preventively, which is determined by the total number of inhabitants multiplied by 1 minus the evacuation fraction. Mortality functions, which are used to calculate loss of life, are a function of water depths (Jonkman 2007, Maaskant et al. 2009b), velocities and rise rates. Recent research shows that also the location and circumstances where people are exposed (in a house, a shelter, on the road) influence loss of life (Kolen et al 2013).

The Dutch programs 'Water and Evacuation' and 'Wave2020' focused on the improvement of emergency preparation. Effort has been placed to improve information management, evacuation preparation, decision making and to increase risk awareness among professionals and citizens. The question is however how to incorporate these measures into account in a quantitative risk assessment. The City of Dordrecht has described their strategy in their water safety plan. The water safety plan also includes an investment agenda in the field of crisis communication that should increase the evacuation effectiveness in time. Dordrecht uses the PBL evacuation and loss of life model to determine what results can be expected by adopting a certain evacuation strategy. The PBL model (Pleijter and Kolen 2016) is a macro model which means the population is considered as a whole instead of modelling each person separately. In the PBL model the warning diffusion curve and personal action initiation curve are combined into a single departure curve.

The United States Army Corps of Engineers (USACE) collected data from numerous evacuations and defined important factors that influence the warning issuance delay time, warning diffusion time and personal action initiation time. From these studies they developed an assessment method which includes a questionnaire that can estimate the expected warning issuance delay time, warning diffusion time and personal action initiation time for an area.

\section{Models}

The PBL model is built on the functions of Jonkman (2007) and Maaskant et al. (2009b), but takes different locations into account where people can be exposed to flood water (during evacuation by car or foot, in a public shelter, prepared or unprepared at home). For the case of Dordrecht the PBL model is used evacuation scenarios of the HIS evacuation calculator (Zuilekom et al 2005).

The PBL model can be categorised as an empirical macro model that divides the population over several victim categories that are based on the expected location of the victim. Each victim category then receives a specified mortality rate which is based on Jonkman (2007) and Maaskant et al. (2009b) and is applied to flood scenarios. The different victim categories are (see Table 2):

1. Victims due to preventive evacuation (traffic accidents, stress on vulnerable people).

2. Victims hit by a flood during evacuation:

- Overtaken by the flood: Victims that are overtaken by the flood during evacuation.

- Shelter in surroundings: Victims that are overtaken by the flood but manage to find shelter in their surroundings at the last possible moment (houses or high ground).

3. Shelters: Population that is hit by the flood while in a predefined public shelter.

4. Those staying at home: The population that does not evacuate and stay in their own home or in the home of others. A distinction is made between people who are prepared and unprepared for the incoming flood.

With the PBL model it is possible to determine the loss of life caused by a flood while incorporating different evacuation strategies like preventive and vertical evacuation as a function of time. In the PBL model for Dordrecht ZIP code areas are used as the smallest entity, meaning a certain ZIP code area can only evacuate preventively or vertically. In a city or area, these two evacuation strategies can thus be mixed for an optimal expected result. Where the most threatened areas will evacuate and less dangerous area's shelter in place. 


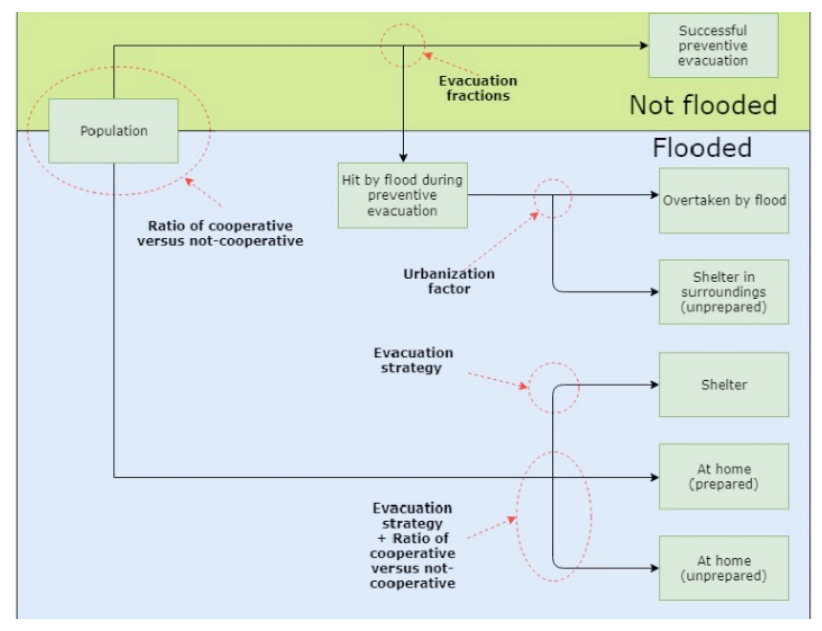

Table 1: Overview of PBL model (Pleijter and Kolen 2016)

In LifeSim each individual person is modelled and accounts explicitly for the impact of warning issuance time, warning diffusion time, the population at risk's behaviour and evacuation potential, detailed flood dynamics and loss of shelter on loss of life (USACE 2018). Each individual is tracked throughout the warning and evacuation process. It incorporates a Monte Carlo sampling technique to capture the natural and model uncertainty in the warning and evacuation process. LifeSim is closely interwoven with the USACE assessment method. The model requires data of flood data, structure inventories, emergency planning zones, road network, destinations and alternatives.

The USACE assessment method is a questionnaire provided by the USACE assessment method are quantified to scores that can be used to generate the warning issuance delay, warning diffusion time and personal action initiation curves. The curves generated from this assessment method include an uncertainty range. The warning issuance delay time is the time it takes for decision makers to reach a decision to issue a warning once they detected the hazard or have been notified of the hazard by those monitoring for it. The warning diffusion represents the process of how efficiently information spreads through the population at risk. The protective action initiation is the time between when an alert or warning is received by a person at risk and the initiation of a recommended protective action by that person.

\section{Case study for the area of Dordrecht}

The city of Dordrecht has developed an evacuation strategy. The basic approach (vertical prepared) is that everybody shelters in their own home or neighbourhood, even without warning because they are aware. In this strategy it is considered that $20 \%$ of the people will not cooperate and evacuates preventive. The required time for traveling to a safe place in the neighbourhood or to a higher floor is limited so people can also take some preparatory measures to reduce their vulnerability.
Preventive evacuation is not possible in many cases because of limited warning time and the overcrowded (national) road network. If the case that more time is available, additional measures will be taken such as evacuating the areas where loss of life is expected to be highest.

In case of a wrong call, when it is decided for preventive evacuation and the warning time is limited al lot of people can be exposed. The number of loss of life in such a case can increase by a factor 10 or more than in the case of a vertical evacuation strategy.

\subsection{Application of USACE assessment method to improve the departure curve for the area of Dordrecht}

After application of the assessment method with the safety region in Dordrecht is concluded that the USACE assessment method contains valuable information regarding what factors influence the required time for evacuation. The method can be a starting point to develop an assessment method applicable to the Netherlands. Elements which needs more research for the Netherlands are:

- The departure curve that follows from the USACE assessment method starts of much faster than the departure curve of the PBL model but takes longer to complete. A possible explanation could be that the departure curve is based on mainly dam failure in the US and in the Netherlands on threats for extreme water levels on rivers or storm surges which have a longer lead time.

- The decision command structure is currently not considered for the warning issuance delay time. For the Netherlands it is expected that this decision command structure is one of the most important parameters that will influence the warning issuance delay time. This is because of the numerous parties involved in the decision-making process. The assessment method developed for the Netherlands has to include a more extensive review of the command structure and how the different parties interact with each other. Because there is not enough data available on evacuations in the Netherlands, the estimations on the warning issuance delay time should be based on expert opinion which can be supported by holding exercises and tests.

- The role of social media. The data used to develop the assessment method is from the period before social media.

\subsection{Model comparison between LifeSim and PBL for the area of Dordrecht}

The current departure curve used in the NL risk assessment is based on HIS-EC and is shown in Table 3. We considered a slow departure curve (all people depart in 16 hours) and a fast departure curve (all people depart in 8 hours). In the case for Dordrecht this departure curve is used to estimate the number of people which can 
evacuate with LifeSim and the PBL method. The time needed for evacuation modelled in LifeSim model is presented in Table 4, we considered different alternatives which distinguish:

- A vertical and preventive strategy for evacuation. For the strategy vertical evacuation still 23.500 people evacuate preventive. For the strategy preventive evacuation 93.500 will leave the area of Dordrecht.

- Optimistic and realistic boundary conditions. Optimistic means a free outflow on the surrounding highways, in the realistic approach it is considered that the surrounding areas also evacuate by the same highways.

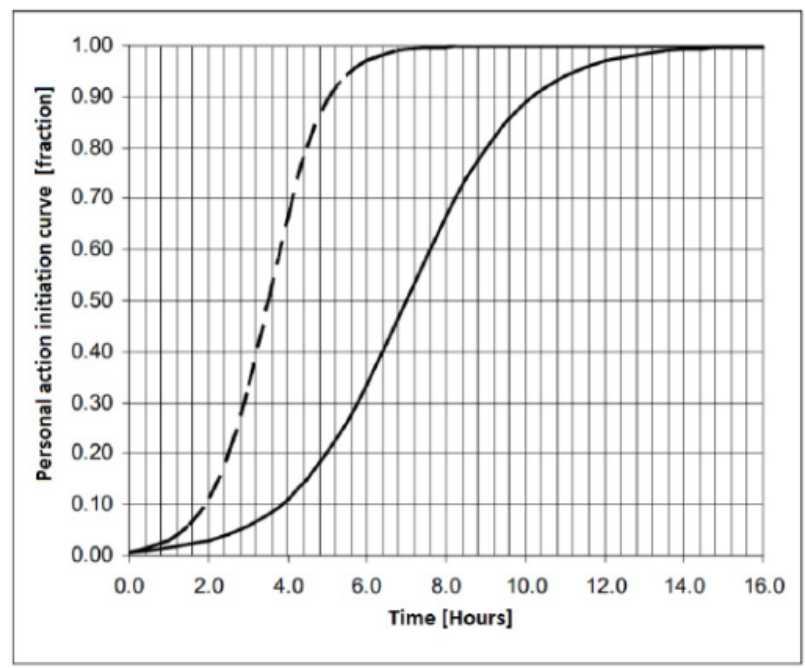

Table 3: Departure curve slow (normal line) and fast (dotted line) (after Zuilekom et al 2005)

\begin{tabular}{|l|l|l|l|l|l|l|l|l|}
\hline & \multicolumn{3}{|c|}{ Slow departure curve } & \multicolumn{4}{c|}{ Fast departure curve } \\
\cline { 2 - 9 } & $25 \%$ & $50 \%$ & $75 \%$ & $100 \%$ & $25 \%$ & $50 \%$ & $75 \%$ & $100 \%$ \\
\hline Alternative 1: Vertical optimistic & $\sim 5.5$ & $\sim 7.5$ & $\sim 9$ & $\sim 16.3$ & $\sim 3$ & $\sim 4$ & $\sim 5$ & $\sim 8.35$ \\
\hline Alternative 2: Vertical realistic & $\sim 6$ & $\sim 9$ & $\sim 11.5$ & $\sim 18.15$ & $\sim 3.5$ & $\sim 6$ & $\sim 8.5$ & $\sim 14.25$ \\
\hline Alternative 3: Preventive realistic & $\sim 10.5$ & $\sim 19.5$ & $\sim 29$ & $>48$ & $\sim 9.5$ & $\sim 18.5$ & $\sim 27.5$ & $>48$ \\
\hline
\end{tabular}

Table 4: Evacuation time (hours) for different percentages of the evacuating population following the reference models.

A faster departure curve can result in significant time savings (and reduction in loss of life), but only in scenarios where there is little traffic congestion. If there is much traffic congestion traffic jams will develop and the travelling time of the population starts to increase. The time saving of a faster departure curve are nullified because although people will leave faster, they immediately enter a traffic jam. In a realistic case when all people from surrounding areas also evacuate this is even worse. National traffic management, combined with a national evacuation strategy which makes choices which area can evacuate preventive or vertical could reduce loss of life and increase effectiveness of evacuation, however such a strategy is not in place yet.

Due to a partial vertical evacuation an overload of the road capacity can be avoided, the departure curve become important. In such a case more people can evacuate and the risk that people are trapped during evacuation reduces. For vertical evacuation where $20 \%$ of the population of Dordrecht leaves, a departure curve that is 8 hours faster will only result in a 4-hour faster evacuation. For preventive evacuation where $80 \%$ of the population leaves the time savings of a faster departure curve are negligible. Table 5 shows a comparison between the $\%$ people that can evacuate as calculated by the PBL model and LifeSim in the case of a preventive evacuation with realistic outflow conditions. The results are almost equal, mainly because of the limited outflow capacity.

\begin{tabular}{|l|c|c|c|c|}
\hline & \multicolumn{4}{|c|}{ Time in hours } \\
\hline \% of total population that has evacuated & 12 & 24 & 36 & 48 \\
\hline Water safety plan Dordrecht & $\sim 25 \%$ & $\sim 60 \%$ & $\sim 70 \%$ & $\sim 78 \%$ \\
\hline LifeSim & $\sim 23 \%$ & $\sim 50 \%$ & $\sim 70.5 \%$ & $\sim 79 \%$ \\
\hline
\end{tabular}

Table 5: Evacuation percentages of the total population for preventive evacuation on different time intervals between the water safety plan of Dordrecht and the LifeSim model.

\section{Concluding remarks}

This study showed that the USACE assessment method is not directly applicable to estimate the effectiveness of preparatory measures related to the departure curve. Despite the method offers a step by step approach which can be translated to the Dutch situation and offer a guideline to estimate the impact of the recent improvements by emergency planning.

For the area of Dordrecht is concluded that improvements of the departure curve are not most critical. To improve the effectiveness of effectiveness of evacuation in Dordrecht the process of decision making within the crisis management structure and a combination of a national traffic management and evacuation strategy is more effective. The time needed for decision making can be shortened, which will increase the time for evacuation. The national evacuation strategy and national traffic management is about how we evacuate. The national evacuation strategy aims to minimize overall loss of life and give boundary conditions for which area can evacuate vertical or preventive. This could result in another strategy than the combination of regional strategies. The national traffic management is required to optimize the use of the national road capacity. The result for Dordrecht is an optimal capacity of surrounding highways which can be used to develop the local evacuation strategy. Improvements of the departure curve become significant when free road capacity can be used.

This study showed that agent-based and macro models can be applied to define the effectiveness of evacuation. For situation with a very high congestion the added value of (more time consuming) agent to define the number of people who can evacuate is limited to macro models. The travelling time is relative long (and the travel speed is slow) compared to the warning issuance delay time and departure curve. A departure curve that is one hour faster in scenarios where it takes more than 48 hours to evacuate the island is negligible. However, if areas manage to (severely) decrease the travelling time of the population by adopting a nationwide vertical evacuation 
strategy, these agent-based models may lead to new insights because they can more easily include area specific information.

\section{References}

1. ENW (2017) Fundamentals of flood protection.

Expertisenetwerk waterveiligheid. URL https://www. enwinfo.nl/images/pdf/Grondslagen/GrondslagenEN -lowresspread3-v.3.pdf.

2. Jonkman S.N. (2007). Loss of life estimation in flood risk assessment; theory and applications. $\mathrm{PhD}$ thesis, Civil Engineering and Geosciences TU Delft.

3. Kolen, B. Kok, M. Helsloot, I. Maaskant, B. (2013). EvacuAid: a probabilistic model to determine the expected loss of life for different mass evacuation strategies during flood threats. Risk Anal. 2013 Jul;33(7):1312-33.

4. Kolen, B. Maaskant B., Terpstra, T. (2013) Addendum evacuatieschattingen Nederland. HKV Lelystad.

5. Maaskant, B. Jonkman, S.N. Kok, M. (2009b) Analyse slachtofferaantallen $V N K-2$ en voorstellen voor aanpassingen van slachtofferfuncties. Rijkswaterstaat.

6. Maaskant, B. Kolen, B. Jonkman, S.N. Kok, M. (2009a) Evacuatieschattingen Nederland. HKV Lelystad.

7. Mileti, D.S. Sorensen, J.H. (2015). A Guide to Public Alerts and Warnings for Dam and Levee Emergencies. US army corps of engineers, Risk management center.

8. Pleijter, G. Kolen B. (2016). Effect van evacueren in SSM. HKV, Lelystad.

9. USACE (2018). User's manual HEC-LifeSim, US Army Corps of Engineers.

10. Van Zuilekom, K.M. Maarseveen, M.F.A.M. (2004) Preventieve evacuatie van dijkringgebieden.

11. Van Zuilekom, K.M. Maarseveen, M.F.A.M. van der Doef, M.R. (2005). A Decision Support System for preventive evacuation of people. In Geo-information for disaster management, edited by P. Zlatanova Van Oosterom, S. Fendel, E. M.: Springer Berlin Heidelberg. 